\title{
The entry cost shock and the re-rating of power prices in New South Wales, Australia
}

\author{
Paul Simshauser, Elizabeth Molyneux \& Michelle Shepherd* \\ Corporate Affairs, AGL Energy Ltd \\ Level 22, 101 Miller Street \\ North Sydney, NSW, 2060.
}

\begin{abstract}
An earlier version of this article formed part of a March 2009 regulatory submission by AGL Energy Ltd to the New South Wales (NSW) Independent Pricing and Regulatory Tribunal (IPART) in relation to their review of retail electricity prices. AGL Energy Ltd services approximately 300,000 of the 3.5 million electricity customers in the NSW region of the National Electricity Market (NEM). AGL does not own any generating plant in the NSW region of the NEM. In May 2009, IPART announced that retail electricity prices would increase by $21.7 \%$ for FY10.
\end{abstract}

\begin{abstract}
Australia has long been the beneficiary of low, stable power prices. A decade-long state of oversupply underpinned this result, and while plant capital costs had been rising, the cost of capital had been declining. These offsetting effects locked the wholesale market into an average cost of \$35-\$40/MWh. However, from 2007 a simultaneous and sharp rise in new entrant plant capital costs and the cost of capital occurred. The combined effects crept-up on the industry while it was in a state of oversupply. This 'entry cost shock' disrupted a 7-year long equilibrium price with average power system cost rising to $\$ 60 / M W h . .$.
\end{abstract}

\section{Introduction}

Electricity prices in the New South Wales (NSW) region of the National Electricity Market $\left(\mathrm{NEM}^{1}\right.$ ) have been extremely stable and among the lowest in the world. ${ }^{2}$ As has been characteristic of the Australian east coast grid, NSW commenced its reform process with a vast oversupply of high quality generating plant capacity. This was a key driver of the industry's enhanced economic performance - the oversupply capped prices at efficient levels largely reflecting what was thought to be industry long run marginal costs at about \$35-\$40/MWh. But in 2007, widespread droughts led to a sharp increase in the level and volatility of wholesale electricity prices. When weather conditions subsided in early 2008, prices moderated from their record highs but converged at materially higher levels than those witnessed in the pre-drought period. A key question that faced generators, retailers, governments and regulators alike was whether or not a material step change in underlying costs had occurred? The analysis presented in this paper argues that it had; the drought brought the entire NEM's demand-supply balance into sharp focus, and consequently all market participants rapidly turned their attention to the task of new plant development and the cost of new power plant - something that had not been undertaken simultaneously and uniformly across the power grid for several decades. This industry-wide process revealed a non-trivial increase in industry long run marginal costs and these new entry costs subsequently began to embed themselves into forward electricity prices. Accordingly, an 'entry cost shock' had been revealed.

\footnotetext{
* Paul Simshauser is also Adjunct Professor of Finance, Griffith Business School, Griffith University. The authors are grateful to Simone Haslinger (Deutsche Bank AG, Equity Capital Markets) and Brad Peel (Deutsche Bank AG, Debt Capital Markets) for their help in collating capital markets data. We are also grateful for helpful comments on earlier drafts from Vijendra Satkunasingam (ANZ), David Gray, Dr Thao Doan (Stanwell), Robert Ludecke (BNP Paribas) and Ben Lacey (QGC). Any errors or omissions remain the responsibility of the authors.

${ }^{1}$ NEMMCo provide a useful background document on the mechanics of the NEM in their publication "An introduction to Australia's National Electricity Market” which is available at www.nemmco.com.au/about/000-0286.pdf

${ }^{2}$ See ESAA (2003) for details. Australia ranked second (with NSW lowest in Australia) behind South Africa.
} 
The purpose of this article is to demonstrate that a material shift in the entry cost of new power plant had occurred between 2004 and 2009. In doing so, we analyse the economics of new entrant plant in the power generation sector and thus define the 'centre of gravity' for forward power prices. We also examine an underlying 'systemic risk' that appears to be emerging in the NSW region of the NEM. This paper is structured as follows; Section 2 provides a 50-year history of power prices in NSW. Section 3 then reviews forward prices in the wholesale market from 2000 to the start of 2009. Section 4 provides a quantitative analysis of the 'overnight capital cost' of new entrant plant in Australia over the same period. Section 5 analyses the cost of debt and equity capital and culminates in a comparative analysis of the marginal efficiency of capital for a merchant power project in the NEM. Quantitative results produced in Sections 4and 5 are then combined and utilised in a Levelised Cost Model and a Dynamic Partial Equilibrium Model of the power system, with the results for plant marginal costs and system average costs for NSW presented in Sections 6 and 7 respectively. Section 8 provides the quantitative evidence of the historical mismatch between wholesale costs and regulated retail tariffs by reviewing ETEF load and customer turnover data. Section 9 then analyses systemic risks inherent in the NSW region of the NEM, and Section 10 examines prior lessons from regulatory failures in energy markets, and policy implications and conclusions follow.

\section{The history of power prices in New South Wales}

The history of power prices in NSW has been one of a continual downward trend over the 50year period between 1955 and 2004 in real terms, as illustrated in Figure 1. This reflects a range of factors common to the east coast of Australia including technological advances of power generating systems, substantial increases in the scale of plant with unit sizes increasing from 30MW to 660MW turbogenerators, and improvements in the aggregate system load factor arising from mining and manufacturing sector loads. Figure 1 presents two NSW price traces which represent average end-user prices. The first is expressed in constant 2004 dollars and starts at $\$ 267.17 / \mathrm{MWh}$ in 1955 and falls to $\$ 77.86 / \mathrm{MWh}$ by 2004 . The second is expressed in nominal dollars and starts at $\$ 21.70 / \mathrm{MWh}$ in 1955 and rises to the 2004 result of $\$ 77.86$. Note that NSW electricity prices have risen by $49.92 \%$ of the Consumer Price Index over the period under examination. The unit price of power experienced a gradual increase during the second half of the 1970s which coincides with the inflationary impacts of the OPEC oil price shocks in 1973 and in 1978. But perhaps the most important characteristic of the line series in Figure 1 is the sharp increase in electricity prices that occurred during the mid-1980s. This was driven by the virtual monopoly pricing capabilities and of the State Electricity Commission ${ }^{3}$ and a significant increase in the generation capital stock employed within NSW, relating specifically to the commissioning of 4 x 660MW units at Eraring and 4 x 660MW units at Bayswater during 1982-1984 following severe blackouts in the early 1980s. To put the extent of this expansion into context, in 1977 the aggregate value of the NSW generating plant was about $\$ 900$ million. 10 years later, the aggregate power generation capital stock in the State had increased 6-fold to $\$ 5.750$ billion. For comparative purposes, also depicted in Figure 1 are the nominal electricity prices for Victoria and Queensland. Unfortunately this data series ceased to be published in 2005 and thus for the intervening period we must turn to wholesale market data.

\footnotetext{
${ }^{3}$ See in particular Figure 4 in Simshauser (2005) which illustrates the direction of electricity prices under monopoly conditions.
} 
Figure 1: $\quad$ 50-year history of average electricity price in New South Wales

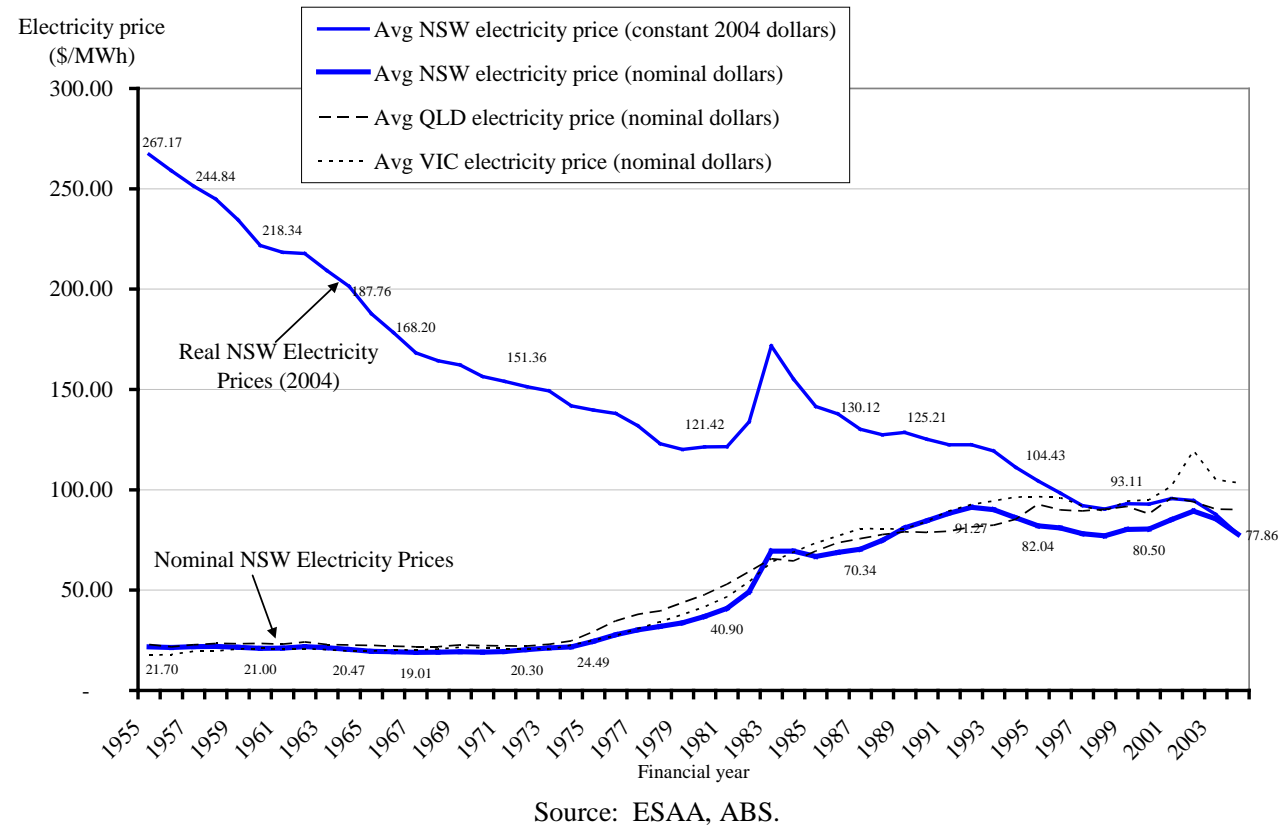

\section{Wholesale power prices in New South Wales}

Historically, NEM base load power prices have tended to gravitate towards the (perceived) long run marginal cost of power generation plant at the long-end of the forward curve. In the case of New South Wales and indeed the wider NEM, this was thought to be between \$35-40/MWh over the period 2000-2007 and is aptly illustrated by the convergence of seven years of 10 distinct traded forward price instruments in Figure 2. However, the drought which began to bind from April 2007 had a material effect on wholesale power prices and led to sudden, albeit transient, capacity constraints throughout the electricity grid. It would prove to mark 'an early end' to the oversupply era that the NEM had inherited from the previous state-based monopoly regimes.

Figure 2: $\quad$ Forward prices (Sep-2001 to Jun-2009) for NSW base swaps

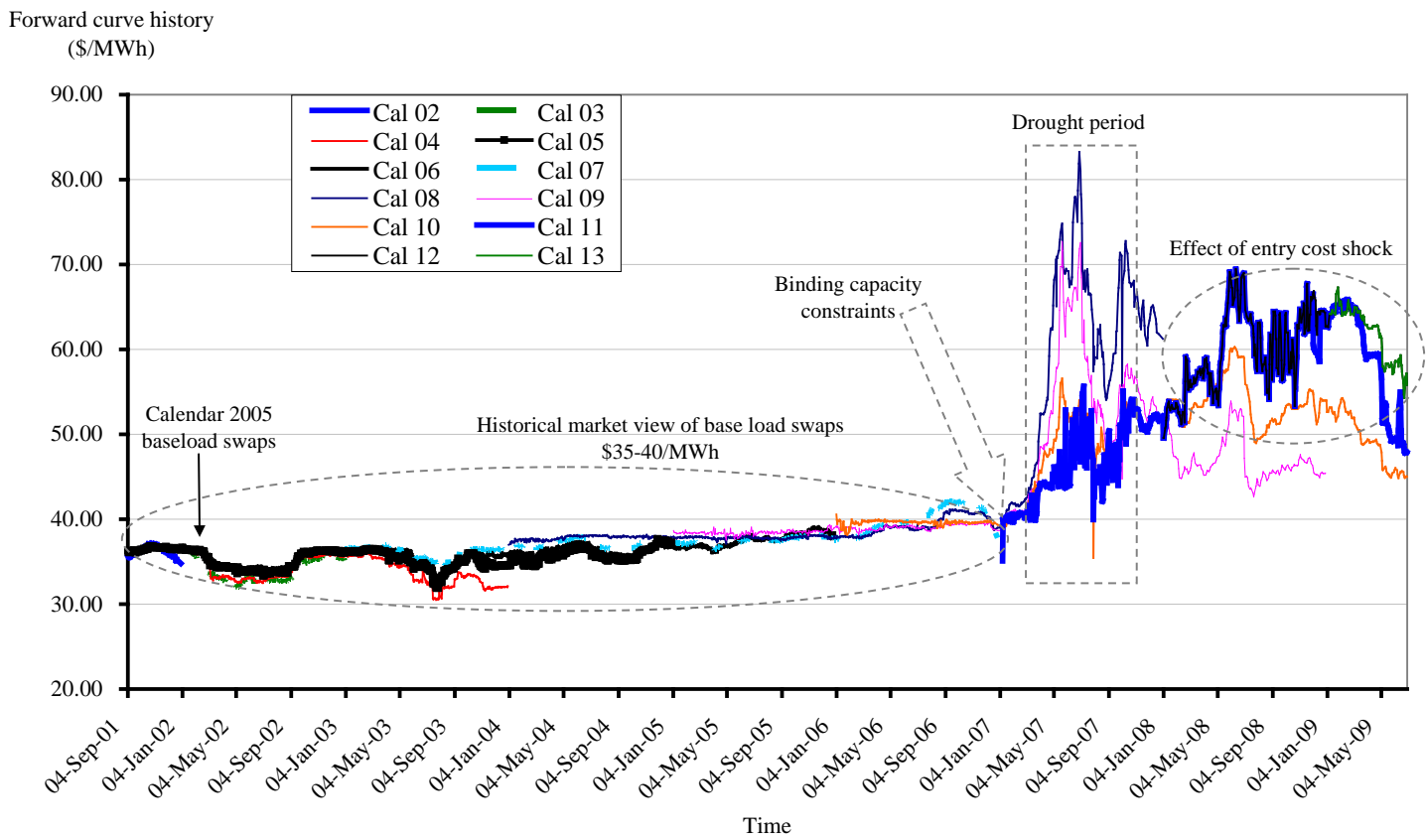

Source: Australian Financial Markets Association. 
The manner in which to interpret Figure 2 is by tracing each hedge instruments' relative value (yaxis) over the time period leading up to the start of the instrument trading date (x-axis). So for example, Calendar 2005 (Cal05) base swaps are visible from the start of the time series (04-Sep01) as the thick bold line at a starting strike price of $\$ 36.20 / \mathrm{MWh}$. Cal05 swaps reach their highest level in November 2004 at a value of \$37.69/MWh, and then cease to be traded from 31 December 2004 - the commencement of its settlement period. Note from Figure 2 that in the main, 'Cal Year' instruments tend to gravitate towards \$35-40/MWh up to April 2007 - that being the 'perceived' long run marginal cost of new entrant power plant. Historically, the \$3540/MWh statistic did have considerable justification, as quantitative modelling results later in this article reveal.

\section{Cost-shock in the manufacturers market \& the cost of new plant}

Just as the water crisis was driving energy shortages in the NEM, ratings agency Standard and Poor's (2007) released a paper which flagged non-trivial increases in the cost of new power station equipment and construction in the United States. Although viewed through the lens of credit analysis, the information found its way into the forward models of energy traders and power industry analysts in Australia. The report noted that new plant capital costs had increased by more than $50 \%$ in the prior three years, driven by a $70 \%$ rise in the price of steel, a $15 \%$ rise in the price of cement, and most importantly, labour shifting from $25 \%$ of component cost to over $40 \%$. The article observed that new entrant costs for Super Critical pulverised fuel (SCpf) base load coal plant had increased in the United States from around US $\$ 1500 / \mathrm{kW}$ in 2003 to US\$2500/kW in 2007. The return of European, US, Australian utilities to the turbine markets after a decade of relative inactivity (following the wave of power industry reforms globally) also served to materially tighten the manufacturer's market dynamics. In particular, manufacturing queues re-emerged for turbine orders which spanned several years and of course they did so in the context of a requirement for technology advancement in the form of higher efficiency plant given emerging greenhouse constraints. ${ }^{4}$ Until this point, it had not been transparent to the broader power market in Australia that the cost of new plant had been rising so quickly. The reasons for this were simple enough:

1. Power station capacity additions were comparatively minimal between 2000 and 2007 due to the oversupply that already existed from the pre-reform era and thus there was no transparency of rising capital costs ;

2. New plant capital costs are not formally reported by any agency in the NEM; and

3. New plant capital costs are not disclosed by entrants in a consistent manner.

This latter point is extremely important to the subsequent analysis and requires detailed explanation. While the cost of a new power station is invariably reported to the financial press, frequently only the main construction contract is cited as the cost which in turn understates total costs by a non-negligible amount. The cost of a new power station essentially comprises the main construction contracts (i.e. the power island ${ }^{5}$ and the balance of plant contracts, which in some cases is combined to form an Engineering, Procurement and Construction or EPC Wrap), site acquisition, planning and permitting costs, pre-development costs, electricity grid connection, gas pipeline connection costs, project development fees, project management fees, aggregate

\footnotetext{
${ }^{4}$ For example, in 2007 a 150MW Gas Turbine from Alstom had a manufacturing 'order queue' of 12-18 months additional lag while larger steam turbines had 'order queues' of almost 3 years. The issue here was that when Europe, US and Australia began their processes of power system deregulation, it was in response to a common problem - the vast oversupply of plant following a surge in monopoly-built capacity during the 1980s (which also occurred in NSW, as discussed in Section 2). Once reforms were implemented from mid-1990s, power development activity plunged in the EU, US, Australia as deregulated markets cleared the oversupply. With the reform process having been reasonably well synchronised globally in the mid-1990s, the time at which jurisdictions found their grids short supplied also appeared to synchronise, from 2006 onwards, which is when order queues began to emerge. However, with deregulated markets one would expect a more stable and predictable demand for turbines going forward.

${ }^{5}$ The Power Island is defined as the core components of a generation plant (i.e. boiler, turbine, generator) whereas the Balance of Plant comprises auxillary equipment (e.g. feed-heating, fuel processing, cooling systems and so on).
} 
commissioning costs (including fuel consumed), project contingencies and interest costs capitalised during construction. The most recent example of this confusion was associated with Origin Energy's 630MW Combined Cycle Gas Turbine (CCGT) project announcement. Origin's initial “ASX Announcement” noted the 'plant' would cost $\$ 780$ million or $\$ 1238 / \mathrm{kW}$. However, the "Project Fact Sheet" released by the company in conjunction with the ASX announcement clearly identified that the $\$ 780$ million statistic was the EPC plant cost. The 'total project cost' was recently reported by Origin Energy to be $\$ 1$ billion or $\$ 1587 / \mathrm{kW}$, with 'other costs' equating to $28.2 \%$ of the EPC contract. ${ }^{6}$

The data compiled and presented below provides a comparative analysis of new coal, CCGT and Open Cycle Gas Turbine (OCGT) plant capacity additions drawing from publicly released data

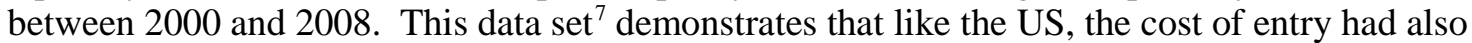
risen sharply in Australia. Capital costs outlined below are an 'overnight capital cost' (i.e. as if built overnight) and incorporate all the costs associated with a newly completed power station, including interest capitalised during construction (IDC). ${ }^{8}$ Figure 3 also includes a CPI cost trace for OCGT plant using 2000 as the base year for comparative purposes. Note that using Oakey OCGT as the base and projecting those costs forward according to the Australian Consumer Price Index, plant capital costs as at 2008 would be around $\$ 700 / \mathrm{kW}$ (up 30\%) compared to the actual result of $\$ 1122 / \mathrm{kW}$ (up 113\%). This rise is consistent with the rise in the power plant cost index for the North American market of $130 \%{ }^{9}$ over the same period. The final data series contained in Figure 3 and measured on the right-hand y-axis is the 'cost of capital' - the calculation and importance of which becomes clear in Section 5.

The recent cyclical downturn in steel prices in line with the global financial crisis raises logical questions over whether the capital cost of power plant equipment might also decline from $2009 .{ }^{10}$ Our 2009F 'Forecast' of plant costs assume a 20\% deterioration in EPC costs.. At face value this might seem moderate relative to the fall in steel prices, but it is worth noting that the power island represents only 70\% of the cost of an Engineering, Procurement, Construction Contract (or EPC Wrap), and as noted in the case of Origin Energy's CCGT plant development, an EPC Wrap represents only $70 \%$ of aggregate plant investment due to other costs, including site acquisition, development costs, connections, project contingency and IDC. Thus, despite a material reduction in the spot commodity price of steel, plant costs will tend to be sticky as a result of other cost components that are unrelated to steel.

\footnotetext{
${ }^{6}$ The $\$ 1$ billion capital cost of Darling Downs CCGT was reported by Macquarie Bank Stock Analyst Gavin Maher on 3 July 2009 "ORG: Queensland asset tour round up”.

${ }^{7}$ CCGT plant required adjustments to ensure a like-for-like comparison, Swanbank E, Tallawarra and Darling Downs reported their Power Island and Balance of Plant costs at $\$ 300 \mathrm{~m}$, $\$ 350 \mathrm{~m}$ and $\$ 789 \mathrm{~m}$ respectively. The aggregate of other costs typically amount to an additional $25-40 \%$ of the project. For the purposes of our analysis, $25 \%$ above Power Island and Balance of Plant costs has been used to represent aggregate project cost.

${ }^{8}$ The importance of 'overnight capital cost' is that it represents aggregate construction costs incurred over the 14-40 month construction period (depending on technology) and critically, includes interest capitalised during construction.

${ }^{9}$ CERA (2008) notes that the power plant cost index is up 130\% between 2000 and 2008. For details, see http://www.cera.com/aspx/cda/public1/news/pressReleases/pressReleaseDetails.aspx?CID=9314

${ }^{10}$ Although anecdotal, our discussions with power developers from Australia and Japan report no decline in the price of new plant, although developers have observed a reduction in the time-delays associated with equipment orders.
} 
Figure 3: 'Overnight capital cost' of new plant - coal, combined and open cycle gas turbines

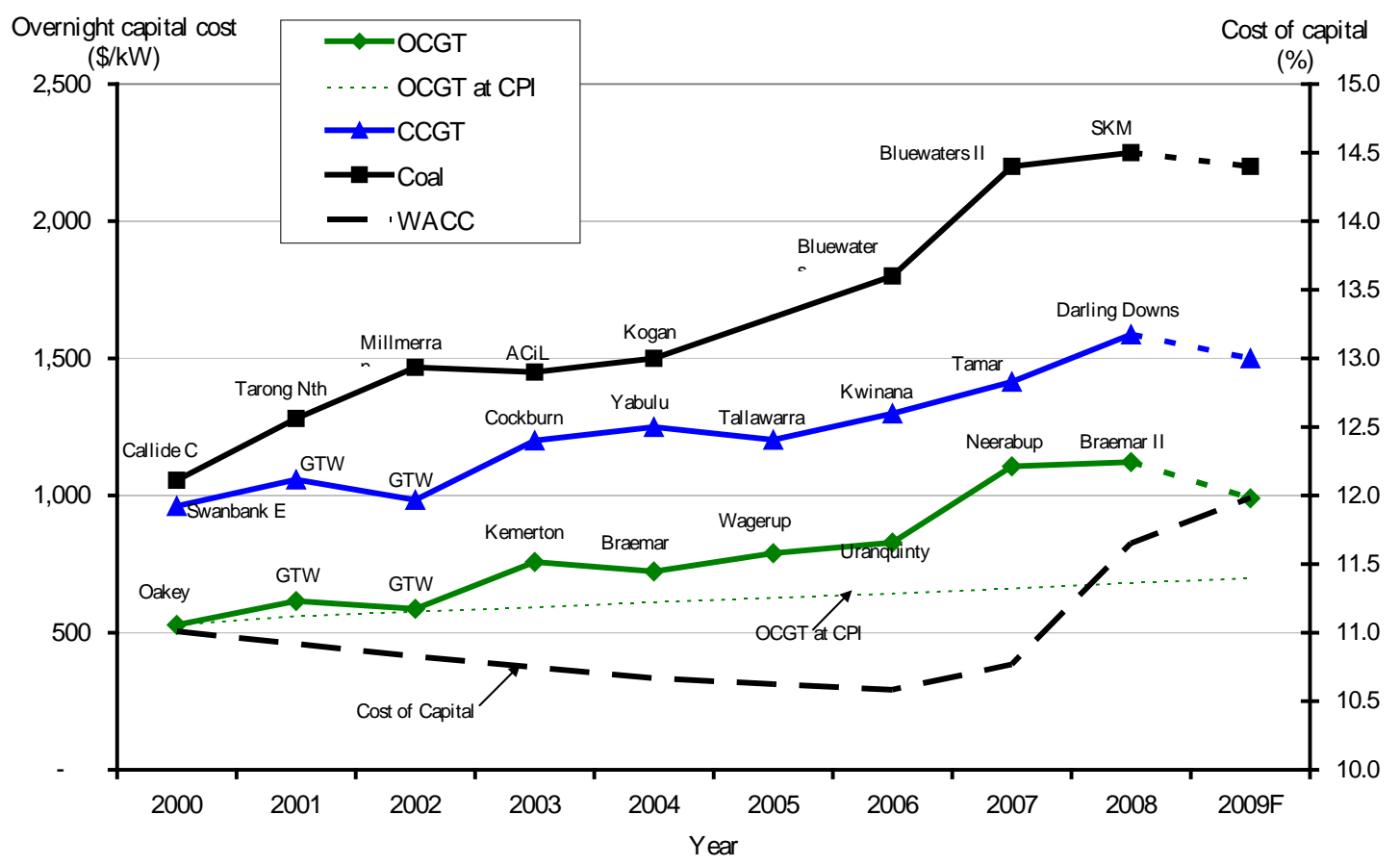

Source: Company ASX \& Media Releases, GTW (2007), SKM (2007), ACiL Tasman (2007, 2008).

Fisher, Newton and Woolnough (2009) produced independent projections of new plant capital costs for Australian in the context of the global financial crisis. They derived coal and gas power plant construction cost indices using approximately 30\% labour, $7.5 \%$ cement, $40 \%$ imported materials and $22.5 \%$ basic metals. This enabled them to adjust for the cyclical nature of steel prices, which had dropped by $40 \%$ following the collapse of Lehman Brothers in September 2008. Fisher et al. (2009) forecast that coal, CCGT and OCGT plant entry cost estimates for 2010 would be $\$ 2249 / \mathrm{kW}, \$ 1227 / \mathrm{kW}$ and $\$ 920 / \mathrm{kW}$ respectively, albeit excluding IDC. ACIL Tasman (2009) arrived at similar costs of $\$ 2291 / \mathrm{kW}, \$ 1368 / \mathrm{kW}$ and $\$ 985 / \mathrm{kW}$ respectively, again excluding IDC. IDC comprises approximately $15 \%$ of the overnight capital cost of a CCGT plant given a 28-month construction period. Henderson (2009) undertook detailed financial modelling to determine IDC for a $\$ 1368 / \mathrm{kW}$ CCGT plant and concluded that it would amount to an additional $\$ 188 / \mathrm{kW}$, taking the ACiL total to $\$ 1556 / \mathrm{kW}$ and the Fisher et al. (2009) total to about $\$ 1400 / \mathrm{kW}$. Consequently, our 2009F data in Figure 3 appear as reasonable estimates for 2009F plant entry capital costs in Australia by comparison to the independent forecasts prepared by ACiL Tasman (2009) and Fisher et al. (2009). Our subsequent quantitative analysis also presents $+/-10 \%$ sensitivity cases to cover credible high and low scenarios.

\section{The capital markets}

The power industry is the most capital intensive industry in the world, and is the third largest user of debt capital behind Governments and the Banking Industry itself (Vaitheeswaran, 2001; Smith, 2008). Consequently, while examining plant capital costs is vitally important, an examination of the cost of capital deployed is also essential as our modelling results indicate that these two variables combined drive approximately $55 \%$ of the aggregate wholesale electricity prices in NSW, given resource endowments. Samuelson (2009) noted that one the intriguing subplots of the global financial crisis was the complete failure of the roughly 13,000 economists in the US to predict it. The crisis originated in the capital markets, but as Samuelson notes, finance occupies only a peripheral position in mainstream economics - being studied by a small sub-set of economists - with the majority focused directly on consumers, business and government. And "if 
you de-emphasise the financial markets and financial markets are decisive, then you're out to lunch” (Samuelson, 2009, p. 55). Similarly in energy market economics, with 55\% of wholesale prices being driven by capital costs and the cost of capital, ignoring the importance of the capital markets would overlook a non-trivial driver of entry costs.

\subsection{Debt capital markets}

In general terms, the cost of debt and equity capital had been declining from the end of the last business cycle in 2002 through to the third quarter of 2007. This is best evidenced by bond yields, swap curves and in particular, Australian Dollar 'BBB rated' credit spreads, all of which are illustrated in Figure 4 along with cash rates (BBSW).

Figure 4: Price trace for bank bill swap rate, 10-year interest rate swaps \& corporate spreads

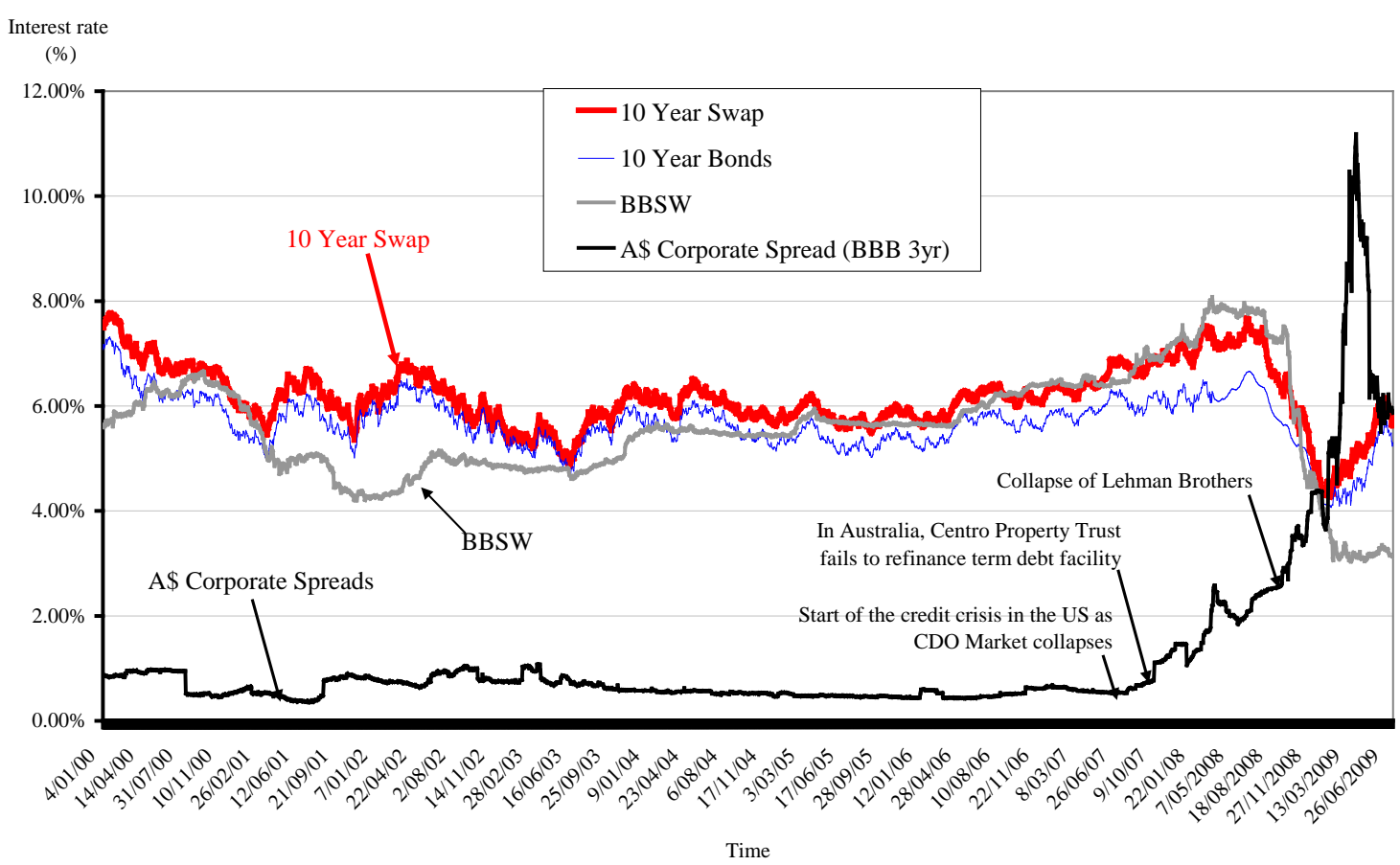

Source: Deutsche Bank AG (Debt Capital Markets, Sydney).

This is important. While the capital cost of power generating plant had been rising, the cost of the capital deployed for generating equipment (10-year swap plus corporate spreads) had been declining between 2002 and 2006 and therefore largely offsetting. This offsetting trend between plant capital costs and the cost of capital was evident in Figure 3, and was statistically correlated at -0.95 . This is a critically important reason for the relative stability in forward electricity prices observed between 2000 and 2006 in Figure 2.

From August 2007, interest rates and corporate spreads had started to rise noticeably following the implosion of the market for Collateralised Debt Obligations (CDO) in the US, which became known as the 'sub-prime crisis'. While local spreads had begun to rise from an unsustainable low of 50 basis points (bps) to about 75bps, liquidity remained relatively unconstrained

notwithstanding the noticeable absence of US-domiciled banks in subsequent debt syndications in Australia. It was as if Australia had side-stepped the worst effects of the CDO market collapse. But the first sign of contagion in Australia came with the failed refinancing of Centro Property Trust's term debt facilities in December 2007. From this point onwards the market progressively deteriorated. And any notion of a side-step was extinguished from 15 September 2008 when US Investment Bank 'Lehman Brothers' collapsed. This was the event that crystallised the credit 
crisis globally. Lehman was simply considered too big to fail but was nevertheless allowed to by the US Federal Government. This triggered the virtual cessation of interbank lending. At the time of writing, only 11 banks in the world held AA credit ratings or better, with four of those being Australian (MacFarlane, 2008).

It was the Lehman Brothers 'liquidity event' that led to the credit crunch in Australia, its implications being a sharp run-up in corporate credit spreads and limited access to debt finance. While the spread data in Figure 4 implies that there has been a significant tightening in access to Debt Capital Markets, the quantitative evidence comes through aggregate 'debt issuance' results. The marked slowdown in liquidity can be seen in Table 1:

Table 1: $\quad$ Global Debt Issuance Results for 2006-2009

\begin{tabular}{|c|c|c|c|c|c|c|c|c|}
\hline Year & 2006 (A\$M) & $\begin{array}{c}\text { (\%chg } \\
\text { QoQ) }\end{array}$ & 2007 (A\$M) & $\begin{array}{c}\text { (\%chg } \\
\text { QoQ) }\end{array}$ & 2008 (A\$M) & $\begin{array}{c}\text { (\%chg } \\
\text { QoQ) }\end{array}$ & 2009 (A\$M) & $\begin{array}{l}\text { (\%chg } \\
\text { QoQ) }\end{array}$ \\
\hline First Quarter & 866,843 & 122 & $1,172,750$ & 35 & 379,696 & -68 & 518,854 & 37 \\
\hline Second Quarter & 844,629 & 105 & $1,072,220$ & 27 & 647,820 & -40 & 458,623 & -29 \\
\hline Third Quarter & 792,885 & 79 & 539,578 & -32 & 222,278 & -59 & & \\
\hline Fourth Quarter & $1,056,483$ & 249 & 374,960 & -65 & 292,640 & -22 & & \\
\hline Total & $3,560,840$ & 130 & $3,159,509$ & -11 & $1,542,435$ & -51 & 977,476 & -5 \\
\hline
\end{tabular}

Global debt issued by banks during the first half of 2007 (H107) was A $\$ 2.245$ trillion and represented an increase of $31 \%$ on H106. Then came the slowdown, the magnitude of which is best captured by comparative Q1 data; between Q108 and Q107 issuance was down 68\%. ${ }^{11}$ The effect of the Lehman collapse is captured during Q308, with the markets again decelerating by $59 \%$ Quarter on Quarter (QoQ).

Yet sustained rises in credit spreads is only part of the issue. Participation by banks has fallen sharply, from 25 to less than 14 as noted in Simshauser, 2009. Another key issue is the length of term facilities. Survey results of project finance bankers published in Simshauser (2009) revealed that the length of money available for power projects has reduced from 12-year to 3-5 year money, and thus the risk of refinancing long-dated infrastructure investments had been heightened and the risk of breaching (tighter) debt covenants had increased. The clear view emerging from the survey was that risk had been materially mis-priced by project banks, and consequently the three year outlook for project finance spreads was found to be 200bps+ with term facilities constrained to 5-7 years at best, a situation reflecting the aftermath of 1991-1993 cycle. An implication from this for the power industry may be a reduction in attainable gearing levels of power projects.

\subsection{Equity capital markets}

The transparency of debt markets makes it comparatively easy to quantify movements in the marginal cost of debt. Finance theory has long been relaxed with the notion that it is far more difficult to make medium term judgements around the expected marginal cost of equity capital. And this has been heightened at the time of writing due to the volatility of listed stocks on the ASX. Nonetheless, before turning to the theoretical constructs of equity pricing, it is useful to examine real world events in relation to the cost of equity via the absolute movement in implied stock yields for the 'Australian universe' of listed infrastructure companies. An analysis of this data is presented in Table 2, with each listed company's implied stock yield as at September 2008 just prior to the collapse of Lehman Brothers, and as at July 2009 for the FY09 reporting period.

\footnotetext{
${ }^{11}$ Sainsbury (2008) reported that Australian debt issuance was also reported to be down by 69\% over the same period.
} 
Table 2: $\quad$ Stock yields from ASX-listed infrastructure securities

\begin{tabular}{lrr}
\hline Security & $\begin{array}{c}\text { Stock Yields as at } \\
\text { Jul 2009 } \\
\text { Jun-09 }\end{array}$ & $\begin{array}{c}\text { Stock Yields as at } \\
\text { Sep 2008 } \\
\text { Jun-09 }\end{array}$ \\
\hline AGL Energy & $4.0 \%$ & $4.0 \%$ \\
APA Group & $11.8 \%$ & $9.8 \%$ \\
ASCIANO & $14.9 \%$ & $6.7 \%$ \\
Aust. Infra Fund & $9.2 \%$ & $7.4 \%$ \\
Babcock \& Brown Infrastructure Gro & $0.0 \%$ & $0.0 \%$ \\
Babcock \& Brown Power & $0.0 \%$ & $0.0 \%$ \\
Challenger Infrastructure Fund & $16.0 \%$ & $12.9 \%$ \\
ConnectEast & $18.1 \%$ & $12.2 \%$ \\
Contact Energy & $4.9 \%$ & $3.6 \%$ \\
DUET Group & $16.6 \%$ & $11.1 \%$ \\
Energy Developments & $5.6 \%$ & $4.5 \%$ \\
Envestra Limited & $15.9 \%$ & $11.8 \%$ \\
Hastings Diversilfied Utilities & $18.4 \%$ & $11.2 \%$ \\
Infigen Energy & $8.5 \%$ & $9.1 \%$ \\
Macquarie Airports & $10.7 \%$ & $10.1 \%$ \\
Macquarie Comm. Infra Grp & $3.4 \%$ & $18.4 \%$ \\
Macquarie Infra. Group & $14.3 \%$ & $8.4 \%$ \\
Origin Energy & $4.2 \%$ & $2.5 \%$ \\
River City Motorway & $18.2 \%$ & $23.7 \%$ \\
SP AusNet & $13.6 \%$ & $11.7 \%$ \\
Spark Infrastructure Group & $15.8 \%$ & $12.2 \%$ \\
Transfield Services Infra. Fund & $12.4 \%$ & $11.8 \%$ \\
Transfield Services Limited & $5.2 \%$ & $5.0 \%$ \\
Transurban & $5.5 \%$ & $4.0 \%$ \\
TrustPower & $5.1 \%$ & $3.9 \%$ \\
Vector & $6.6 \%$ & $6.1 \%$ \\
Viridis Clean Energy & $12.8 \%$ & $8.8 \%$ \\
\hline Average & $10.1 \%$ &
\end{tabular}

Source: Deutsche Bank AG (Equity Capital Markets, Sydney).

Stock yield data from Table 2 indicates that the cost of equity has increased by 130bps. This is not entirely surprising. Equity market participants have suffered significant capital losses and extreme volatility over the course of the past 12 months and are therefore likely to price higher risk premiums for equities, and so pay less for earnings, that is, lower Price-Earnings (PE) Ratios and lower Enterprise Value to Earnings before Interest, Tax and Depreciation (EV/EBITDA) multiples in particular. Consequently, as we turn to the Capital Asset Pricing Model to determine the cost of equity, it is reasonable to expect a marginal increase in the calculated 'expected return' to power station equity holders.

In Table 3, we present a time series of Project Finance margins, debt costs, equity costs and weighted average capital costs using underlying interest rate data from Figure 4 while Project Financing margins have been drawn from live transactions. We have based our equity cost calculations on the works of Officer (1994) which discounts the cost of equity by incorporating the effects of dividend imputation credits. Key assumptions used in the estimation calculation for the cost of equity capital for a merchant power project include a gearing ratio of $65 \%$, corporate tax rate of $30 \%$ with an effective forecast cash tax rate of $21 \%$ (based on the timevalue of cash tax payments), forecast inflation of $2.5 \%$, interest rates prevailing at the mid-point date of each calculation, an implied equity capital market premium of $6 \%$ above long bond rates, power station asset beta $(\beta \mathrm{a})$ of 0.5 and equity beta $(\beta \mathrm{e})$ of 1.41 and imputation credits or gamma $(\gamma)$ of $50 \%$. 
Table 3: Weighted average capital cost for an Australian merchant power project

\begin{tabular}{ccccc}
\hline $\begin{array}{c}\text { Power station } \\
\text { commitment }\end{array}$ & $\begin{array}{c}\text { Project Finance } \\
\text { Debt Margin }\end{array}$ & $\begin{array}{c}\text { Pre-tax cost of debt } \\
\text { capital: 10Yr } \\
\text { Swap+Margins } \\
(\text { Yr) }\end{array}$ & $\begin{array}{c}\text { Post-tax cost of } \\
\text { equity capital - } \\
\text { imputation incl. } \\
(\%)\end{array}$ & $\begin{array}{c}\text { Pre-tax } \\
\text { weighted } \\
\text { average } \\
(\%)\end{array}$ \\
\hline 2000 & $1.40 \%$ & $8.06 \%$ & $13.02 \%$ & $11.0 \%$ \\
2002 & $1.40 \%$ & $7.74 \%$ & $13.08 \%$ & $10.8 \%$ \\
2004 & $1.30 \%$ & $7.45 \%$ & $13.15 \%$ & $10.7 \%$ \\
2006 & $1.10 \%$ & $7.31 \%$ & $13.17 \%$ & $10.6 \%$ \\
2007 & $0.90 \%$ & $7.69 \%$ & $13.02 \%$ & $10.8 \%$ \\
2008 & $1.75 \%$ & $9.13 \%$ & $12.90 \%$ & $11.7 \%$ \\
2009 & $3.50 \%$ & $9.42 \%$ & $13.23 \%$ & $12.0 \%$ \\
\hline
\end{tabular}

The calculations in Table 2 reveal important trend information. Note that the cost of capital was declining to 2006, and rose sharply from 2007-2009. This supports our thematic of coincident rising costs (i.e. plant cost and cost of capital) and is clearly visible in Figure 3. Note also that the comparative the post-tax cost of equity capital has increased in 2009 as expected, albeit with less intensity than the yield data implies in Table 2. To be sure, this is a predictable outcome of the Capital Asset Pricing Model given its reliance on long bond rates to determine headline equity costs. Nonetheless, these results will be used in the subsequent analysis as any variation would be arbitrary, and therefore contentious at best.

\section{Long run marginal cost and the cost of plant entry}

To determine the extent of the shift in the long run marginal cost of plant, we present two distinct calculation points; the first being 2004 to demonstrate that the long-held view of \$35-\$40/MWh was in fact based on sound fundamental analysis; and the second being 2009 which demonstrates that the shift in forward electricity prices outlined in Figure 2 is was supported by fundamental analysis arising from the 'entry cost shock'. Our key plant capital cost data assumptions are as follows:

Table 4: $\quad$ Power station technical and cost assumptions

\begin{tabular}{|c|c|c|c|c|c|c|c|c|c|c|}
\hline $\begin{array}{l}\text { Generation } \\
\text { technology }\end{array}$ & $\begin{array}{r}\text { Capital cost } \\
\text { in } 2004 \\
(\$ / \mathrm{kW})\end{array}$ & $\begin{array}{r}\text { Capital cost } \\
\text { in } 2009 \\
(\$ / \mathrm{kW})\end{array}$ & (MW) & $\begin{array}{r}\text { Variable } \\
\text { O\&M } \\
\text { (\$/MWh) }\end{array}$ & (\$M pa) & Useful life & $\begin{array}{l}\text { Heat rate } \\
(\mathrm{kJ} / \mathrm{kWh})\end{array}$ & $\begin{array}{r}\text { Fuel cost in } \\
2004 \\
(\$ / G J)\end{array}$ & $\begin{array}{r}\text { Fuel cost } \\
\text { in } 2009 \\
(\$ / G J)\end{array}$ & $\begin{array}{r}\mathrm{CO} 2 \\
\text { Emissions } \\
(\mathrm{t} / \mathrm{MWh})\end{array}$ \\
\hline SCpf & 1,500 & 2,200 & 660 & 1.00 & 25.0 & 40 & 9,800 & 1.10 & 1.20 & 0.90 \\
\hline CCGT & 1,200 & 1,500 & 300 & 2.50 & 4.5 & 30 & 7,500 & 3.50 & 4.50 & 0.40 \\
\hline OCGT & 700 & 990 & 150 & 8.00 & 2.0 & 30 & 11,500 & 4.00 & 5.00 & 0.60 \\
\hline Cost of capital: & $10.7 \%$ & $12.0 \%$ & from $T$ & & & & & & & \\
\hline
\end{tabular}

Table 4 capital cost assumptions have been drawn from Figure 3 while the cost of capital has been drawn from Table 3. This data has been entered into a Levelised Cost Model which calculates the long run marginal cost of various generation technology options. The logic of the Levelised Cost Model is underpinned by conventional discounted cash flow analysis and is comprehensively documented in Simshauser (2009) and in Simshauser and Wild (2008) and we do not propose to reproduce the model specifications here. In the model, SCpf and CCGT plant, being energy-biased investments, are assumed to operate at an annual capacity factor of $92 \%$ and average cost results are expressed below in Table 5 as equivalent to a 'Base Load Swap' price. OCGT plant, being capacity-biased investments, are measured by the 'carrying cost ${ }^{\text {' }}$ of plant

${ }^{12}$ SCpf and CCGT plant are energy-based investments in that such investments tend to earn the majority of their returns through the production of energy, whereas OCGT plant are capacity-biased as they earn the majority of their returns through the forward sale of capacity. The 'carrying cost' of plant is defined as the fixed revenue required to satisfy aggregate fixed costs of the plant as and when they fall due. The revenue stream is paid on plant capacity (MW), not plant output (MWh). 
and expressed as an equivalent ‘ $\$ 300 /$ MWh Call Option’ or Cap Contract ${ }^{13}$ in a manner consistent with Boiteux's (1949) seminal works on the peak load pricing problem in the presence of heavy fixed costs:

Table 5: $\quad$ Change in the entry cost of new plant (2004 - 2009)

\begin{tabular}{lccccc}
\hline Techology & $\begin{array}{c}\text { Basis of } \\
\text { measure }\end{array}$ & $\begin{array}{c}2004 \\
(\$ / \mathrm{MWh})\end{array}$ & $\begin{array}{c}2009 \\
(\$ / \mathrm{MWh})\end{array}$ & $\begin{array}{c}\text { Change } \\
(\$ / \mathrm{MWh})\end{array}$ & $\begin{array}{c}\text { Change } \\
(\%)\end{array}$ \\
\hline SCpf & Base Load Swap & $\$ 37.91$ & $\$ 49.79$ & $\$ 11.88$ & $31 \%$ \\
CCGT & Base Load Swap & $\$ 47.32$ & $\$ 60.54$ & $\$ 13.22$ & $28 \%$ \\
OCGT & \$300/MWh Call Option & $\$ 9.38$ & $\$ 13.27$ & $\$ 3.89$ & $41 \%$ \\
\hline
\end{tabular}

Table 5 confirms that there has been a material increase in the cost of electricity production between 2004 and 2009, even after accounting for the 2009F decline in the overnight capital cost of plant. Note that the cost of base plant has increased from $\$ 37.91 / \mathrm{MWh}$ to $\$ 49.79 / \mathrm{MWh}$. This is an important result; recall from Figure 2 that base load swaps had historically traded between \$35-\$40/MWh throughout the 2000-2006 period and thus our 2004 cost estimate of \$37.97/MWh is central to this range. From 2007 onwards, prices jumped and have levelled out at an average of $\$ 50 / \mathrm{MWh}$, which again is in-line with our cost estimate for new base load plant using SCpf technology in 2009. The carrying cost of peaking plant has also increased significantly, from $\$ 9.38 / \mathrm{MWh}$ to $\$ 13.27 / \mathrm{MWh}$ (up 41\%), which will have a non-trivial impact on system average cost, which is analysed in detail in the next section

\section{The shift in system average cost}

In the power industry, the long run marginal cost of production reference to the cost of a new base load plant. There is a material difference between the long run marginal cost of production and system average cost because the latter also includes the cost of intermediate and peak load capacity. Since a power system comprises a combination of base, intermediate and peaking plant (including a reserve plant margin), it follows that system average cost will lie above the long run marginal cost of base plant. We have used the NEMESYS Power System Model to determine system average cost for NSW using 2004 and 2009 plant cost data from Table 4. The NEMESYS Model is a dynamic, partial equilibrium model of a power system with half-hourly equilibrium resolution and serves to optimise the rich blend of fixed and variable costs listed in Table 4 and minimises the aggregate cost of supply and spot price outcomes for a given reliability constraint. The NEMESYS algorithms and specifications have been documented in detail in Simshauser (2008) and again, we do not propose to reproduce them here.

To highlight the change in system average cost, a constant NSW 2008 historical load curve with half-hour resolution has been utilised in both scenarios. In Table 6, the optimal requirement for plant to minimise the aggregate cost of supply as determined by NEMESYS is listed in the second column while the NSW actual plant stock is listed in the third column (with the details of each plant provided in Appendix I). This analysis also accounts for supply via the Queensland and Victorian interstate transmission line interconnects, which in turn heavily discounts the required indigenous system reserve plant margin.

\footnotetext{
${ }^{13}$ Call options, or Cap Contracts as they are commonly referred to in the NEM, provide retailers with insurance against severe spot price spikes. NEM Caps typically have a strike price of either $\$ 100 / \mathrm{MWh}$ or $\$ 300 / \mathrm{MWh}$. Option premiums paid by retailers in exchange for this insurance product are calibrated against the new entrant (carrying) cost of peaking plant. 
Table 6: $\quad$ Plant mix and system average cost using 2004 cost data based on 2008 load

\begin{tabular}{lrrr}
\hline Plant type & $\begin{array}{r}\text { Optimal } \\
(\mathrm{MW})\end{array}$ & $\begin{array}{r}\text { Actual } \\
(\mathrm{MW})\end{array}$ & $\begin{array}{r}\text { Balance } \\
(\mathrm{MW})\end{array}$ \\
\hline Base & 10,400 & 11,290 & 890 \\
Intermediate & 500 & 1,216 & 716 \\
Peak & 3,000 & 1,959 & $-1,041$ \\
\hline Total system & 13,900 & 14,465 & 565 \\
\hline System Average Cost: & $\$ 45.73 / \mathrm{MWh}$ &
\end{tabular}

The 2004 cost results reveal that system average cost (comprising fuel, variable and fixed operation and maintenance costs, debt costs, equity costs and corporate taxation) was $\$ 45.73 / \mathrm{MWh}$, some $21 \%$ higher than the 2004 long run marginal cost of base load plant at \$37.91/MWh. Table 7 replicates this analysis using the 2009 cost data from Table 4:

Table 7: $\quad$ Plant mix and system average cost using 2009 cost data ${ }^{14}$ based on 2008 load

\begin{tabular}{lrrr}
\hline Plant type & $\begin{array}{r}\text { Optimal } \\
(\mathrm{MW})\end{array}$ & $\begin{array}{r}\text { Actual } \\
(\mathrm{MW})\end{array}$ & $\begin{array}{r}\text { Balance } \\
(\mathrm{MW})\end{array}$ \\
\hline Base & 10,100 & 11,290 & 1,190 \\
Intermediate & 1,300 & 1,216 & -84 \\
Peak & 2,500 & 1,959 & -541 \\
\hline Total system & 13,900 & 14,465 & 565 \\
\hline System Average Cost: & $\$ 60.15 / \mathrm{MWh}$ &
\end{tabular}

Note that system average cost has increased from \$45.73/MWh to \$60.15/MWh, up \$14.42/MWh or $31.5 \%$. The $\$ 14.42 / \mathrm{MWh}$ increase is comprised of a capital cost increase of $\$ 10.17 / \mathrm{MWh}$ (70.5\%), a cost of capital increase of $\$ 3.70 / \mathrm{MWh}$ (25.7\%) with higher running costs accounted the balance, at $\$ 0.55 / \mathrm{MWh}(3.8 \%)$.

\section{Retail market effects of the entry cost shock}

The underlying electricity price path for NSW retail customers was originally set for the period July 2007 through to June 2010 by the State Regulator, IPART. At the time in which the initial regulatory analysis was being carried out in 2007, forward contract prices were doubling due to the transient effects of the drought and consequently, regulatory prices were set on a business-asusual basis and a 7\% increase was pre-determined for FY10. An interim review by IPART just prior to the FY10 increase concluded however that electricity prices had increased well beyond $7 \%$ and in the event, revised the increase from $7 \%$ to $21.7 \% .{ }^{15}$ The basis for this was clear enough. As we have demonstrated throughout this article, the simultaneous rise in plant capital costs and the cost of capital had revealed an entry cost shock and thus electricity prices in forward markets were responding to a non-trivial change in market fundamentals.

If IPART had not lifted the regulated retail price, and instead held them at pre- 'entry cost shock' levels, retail margins would have eroded to a point where market contestable contracts were no longer profitable and in the event, contestable customers would have reverted to their 'franchise' retailer. The relevant quantitative evidence of this concept is supported via aggregate Electricity Tariff Equalisation Fund (ETEF) Franchise customer numbers in NSW. By way of brief background, the ETEF is a pooled hedging arrangement between the three NSW State-Owned generators and the three NSW State-Owned franchise retailers, with the ETEF hedge volume

\footnotetext{
${ }^{14}$ We conducted two sensitivity studies against our central capital cost estimates. +/-10\% change to capital costs led to a system average costs of $\$ 63.80 / \mathrm{MWh}$ and $\$ 56.50 / \mathrm{MWh}$ respectively.

${ }^{15}$ It is worth noting that a non-trivial component of the revised aggregate increase was due to increases in the regulated electricity network tariffs.
} 
equivalent to the franchise customer base and the long-standing ETEF hedge price calibrated against the 2007 determination. Accordingly, since the entry cost shock occurred after the 2007 determination, if market-based retail margins were negative, we would expect to see ETEF Franchise customer numbers rising after 2007. Conversely, if regulated prices and retail margins were profitable following the entry cost shock in 2007 (implying no support for a material price increase), then we would expect to see ETEF customer numbers continuing to decline as competitive retailers lured residential customers off the regulated tariff and onto market contestable contracts. Figure 5 presents ETEF Franchise customer number results.

Figure 5: $\quad$ Aggregate ETEF Franchise customers for 2007 and 2008

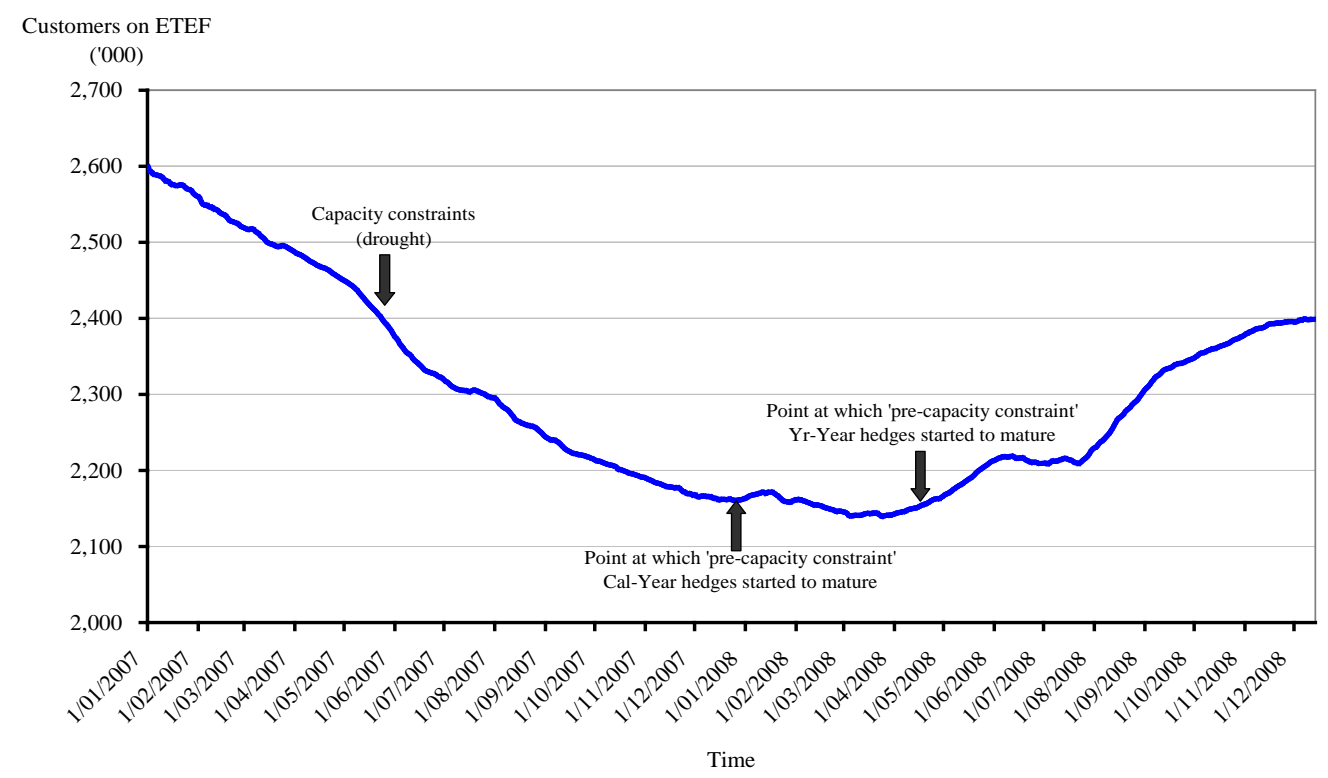

Source: Based on NSW Treasury data (data has been corrected to remove weather effects).

Figure 5 illustrates that ETEF Franchise customer continued to fall throughout the highly volatile 2007 year. This most likely reflects the structure of retailer hedge books, being built up over the pre- entry cost shock period, and perhaps an initial view that the drought was indeed little more than a transient issue. Over time, as the step change change in industry fundamentals and wholesale prices was revealed, and as retailer hedge portfolios faced maturing hedge contracts (typically at the start of each calendar and financial year), directional changes in ETEF Franchise customer numbers became clear as low cost hedges were replaced with high cost hedges. It seems that the first sign of a slow down in ETEF Franchise customer numbers occurred at the end of calendar 2007, with the permanent directional change occurring as FY08 hedge contracts matured (i.e. being replaced with materially higher priced hedge contracts). Interestingly, NEMMCO data also revealed that NSW customer turnover fell below 10\% compared to the NEM average of $20-25 \%$.

In summary then, wholesale market prices experienced a material step change arising from an entry cost shock, and the lag in retail price adjustments manifest itself in a reversal of customers moving from the regulated retail tariff to market contestable contracts. That customers began returning from market contestable contracts back to the ETEF Franchise regulated tariff provided important evidence to IPART in their 2009 determination. Yet the ETEF arrangement has the potential to create more dangerous distortionary effects in the NSW market in that 'systemic security’ issues have been masked - and this is dealt with below, in Section 9. 


\section{System security vs. systemic security}

In simple terms, power system security means 'keeping the lights on' and ensuring the power grid operates in a reliable state. Systemic security means ensuring the financial system that underpins the power grid operates in a stable state. Power system security is a key policy issue for government, policy makers and energy regulators and represents a central point of reference in the annual 'Statement of Opportunities' published by market system operators on both the east and west coasts of Australia (see for example NEMMCo, 2008). The concept of 'NEM systemic security' is not examined by regulatory authorities yet we consider it a material issue facing policy makers in NSW, despite its obscure status in regulatory settings. NEM security should not be viewed narrowly as merely having adequate plant capacity, but also the ability of the buy-side (i.e. retailers) to deal in an energy-only, gross pool electricity market with a market cap of $\$ 10,000 / \mathrm{MWh}$. In order for market participants, particularly buy-side market participants, to maintain a stable operating platform from a financial perspective, it is imperative that adequate sell-side (i.e. generator) hedge capacity exists in over-the-counter and futures markets. In the absence of adequate hedges, spot market payments can quickly exceed the financial capacity of retailing entities ${ }^{16}$ and if a sufficiently large participant were to experience financial distress, it could trigger a 'systemic failure' of the NEM.

There have been periods where regions of the NEM have had inadequate hedge capacity. For example, in Queensland between 2000-2005 the system reserve margin was in excess of 20\% yet with each local generator largely running an ' $n-1$ ' hedge book (i.e. withholding their single largest generating unit from the hedge market for self-insurance purposes) retailers were unable to secure forward hedge contracts in sufficient volumes either locally or via inter-regional hedges at economic rates. But the backing of the State Owned Retailers, Energex and Ergon, by Queensland Treasury implicitly ensured that the notion of 'systemic risk' was effectively nonexistent. In the following analysis, we demonstrate that even with an oversupply of generating capacity in NSW relative to system optimal conditions, the inherent hedging capacity of NSWdomiciled generators is inadequate for the buy-side to construct a balanced hedge portfolio.

As one reviewer noted, the NEM is a national market and therefore at face value, any shortfall of NSW-domiciled hedges should, in theory at least, be met by hedges from other regions. But there are three reasons why these conditions may not hold. First, NSW prices are not perfectly correlated with VIC and QLD prices. ${ }^{17}$ Inter-regional hedges have the effect of insuring against regional price differences, but inter-regional settlement residues are limited to aggregate NSW interconnect capacity of $1700 \mathrm{MW}$ and thus an inherent shortfall (or regional basis risk beyond $1700 \mathrm{MW}$ ) remains. Second, with all portfolio generators across the NEM effectively following ' $n-1$ ' hedging policies for self-insurance purposes, the aggregate surplus 'physical generating capacity' in the neighbouring regions of VIC and QLD do not translate neatly to surplus 'generator hedge capacity' for use in NSW. ${ }^{18}$ And to that end, third, on physical generation, NEMMCO (2008) notes that looming physical shortages exist in VIC in 2009, and that QLD is effectively in balance, which indicates that surplus 'hedge' capacity is unlikely to exist in any event. The implication here is that while the NEM may be adequately supplied with physical

\footnotetext{
${ }^{16}$ This was aptly demonstrated with the financial collapse of ASX-listed retailer 'EnergyOne' in NSW during 2007. EnergyOne was a small retailer with less than 100,000 accounts and the market absorbed this failure without any major disruption via the reallocation of its customer base to State-Owned Retailers in New South Wales under the Retailer of Last Resort mechanisms in the National electricity Rules. Clearly, the failure of a larger retailer of say 1 million+ accounts with multiple generator counterparties would create an entirely different dynamic.

${ }^{17}$ The correlation coefficient between NSW and QLD spot price between 2002 and 2008 was just 0.70, and for NSW and VIC over the same period was 0.84 .

${ }^{18}$ Clearly a single unit generator or even a two unit generator is unable to adopt an ' $n-1$ ' contract position as the volatility of cash flows would literally be 'unbankable' as a merchant investment. Typically in such circumstances, the unit will be contracted entirely to a retailer, who in turn absorbs the risk of unavailability within their own portfolio. Consequently, single unit and two-unit generating companies in the NEM are indeed rare. Most generators in the NEM comprise a diverse portfolio of generating sites and units.
} 
generating capacity to meet system security, the application of ' $n-1$ ' hedging strategies across the NEM implies that the aggregate NEM may have a hedge shortage, which is most likely to manifest itself in NSW as the primary 'capacity importing' region, and thus the NEM, in the NSW region, may not have systemic security.

With this in mind, in our analysis of the NSW region in Section 7 we optimised the use of existing transmission interconnects between QLD and VIC such that 1700MW of capacity was assumed to be reliable (nb. NEMMCo analysis assumes 1724MW) which statistically represents a 99.92\% level of confidence in transmission interconnect capacity. In consequence, NSWdomiciled generating plant capacity in these optimised simulations represented only $97 \%$ of our $50 \%$ Probability of Exceedence $\left(\right.$ PoE50 ${ }^{19}$ ) electricity load. Incorporating reliable transmission interconnect capacity from QLD and from VIC with the optimised NSW generating plant stock resulted in an aggregate $9 \%$ reserve plant margin over a PoE50 demand forecast. Regardless, it is clear from this simple description of the supply-side that with NSW-domiciled generating capacity representing only 97\% of regional PoE50 demand (let alone PoE10 demand), it is impossible for the buy-side to hedge their position through the use of local contracts alone. Withholding of generating capacity for self-insurance purposes by NSW generators will obviously compound the inherent shortfall.

The NEM is now 10 years old and a logical question which follows is why this issue has not appeared earlier in the literature. The reason systemic security rarely rates a mention in NSW is that the Government's ETEF policy, which has been in existence since 2002, has comprehensively shielded the NSW region from any form of systemic risk (notwithstanding the dominance of State Owned retailing entities). As noted above, the elegant structure of ETEF created a pooled hedging arrangement between three supply-side and three demand-side entities, comprising a vast portfolio of generating systems and geographically and therefore weatherdiverse retailing franchise loads - thus diversifying the responsibility and indeed accountability for hedging gains and losses beyond any one market participant. The ETEF policy was never designed for its current length of duty, and consequently it has more recently had the effect of masking this substantive looming issue as demand and supply tightened. Conversely, the ETEF policy is now progressively being retired between now and June 2010, hence the emergence of this systemic issue.

As the aggregate capacity of ETEF progressively reduced beyond the inherent shortfall of natural hedge capacity in the NSW region, wholesale market prices are likely to come into sharp focus given the constraints around adjacent regional hedge capacity. This trend became evident in the QLD case when the supply of hedge capacity fell short of prudent buy-side hedge demand, again despite the fact that QLD formed part of the NEM. The effects were most noticeable between 2003 and 2005 when local generating plant capacity were well in excess to physical requirements, which resulted in low spot prices of circa \$28/MWh, while hedge prices in QLD simultaneously and continuously traded at a $\$ 7 / \mathrm{MWh}$ spread to spot, at about $\$ 35 / \mathrm{MWh}$. The quantitative evidence of this was perhaps best illustrated on the $3^{\text {rd }}$ and $4^{\text {th }}$ of December 2002 when QLD electricity retailer, Energex, was caught short (i.e. under-hedged) by an estimated 1000MW when hot weather patterns drove an equivalent PoE10 demand day, and in the event was said to have incurred losses in excess of $\$ 40$ million over the two trading days. The fact that the retail business formed only a small part of the overall Energex retail and distribution network business, along with financial backing by the State's central borrowing agency (Queensland Treasury Corporation) ensured in this case there was no potential for financial distress.

\footnotetext{
${ }^{19}$ PoE defines the probability by which a point estimate might be exceeded in years. So a PoE50 forecast would be expected to be exceeded one in two years. A PoE10 forecast would be expected to be exceeded one in every 10 years.
} 
Table 8 presents the results of an optimised plant mix for NSW against forecast 2009/10 load data, along with the forecast actual plant stock - again using the NEMESYS dynamic partial equilibrium model to produce the results. Our 2009/10 load forecast has a peak demand of about 14,500MW with a system load factor of 0.66 . The actual plant stock data for 2009/10, including new entrant plant, is contained in Appendix I.

Table 8: $\quad$ Plant mix for 2009/10 with a 9\% aggregate reserve plant margin (incl. interconnects)

\begin{tabular}{lrrr}
\hline Plant type & $\begin{array}{r}\text { Optimal } \\
(\mathrm{MW})\end{array}$ & $\begin{array}{r}\text { Actual } \\
(\mathrm{MW})\end{array}$ & $\begin{array}{r}\text { Balance } \\
(\mathrm{MW})\end{array}$ \\
\hline Base & 10,700 & 11,290 & 590 \\
Intermediate & 1,800 & 1,616 & -184 \\
Peak & 1,700 & 3,159 & 1,459 \\
\hline Total system & 14,200 & 16,065 & 1,865 \\
\hline
\end{tabular}

In this instance, our forecast indicates that relative to optimal conditions, a 1865MW oversupply of NSW-domiciled plant is forecast to exist which creates a 'local generating plant reserve' of about $+10 \%$ (as opposed to a $-3 \%$ optimised local plant reserve). But even this oversupply is insufficient for hedging purposes as it represents physical plant capacity, and not available hedge capacity. Note that because of the asymmetric nature of the gross pool energy market design, with average base prices c.\$50/MWh and the extreme peak at $\$ 10,000 / \mathrm{MWh}$, it stands to reason that when portfolio generators choose a non-ETEF hedge position, they will not hedge beyond installed capacity and in fact will inevitably create a reasonable risk or 'capacity buffer' (e.g. withholding their single largest unit).

In order to predict the reliable level of NSW-domiciled hedge capacity, we have constructed portfolio plant availability curves for the NSW generating fleet, with outage rates of about $6 \%$ for the $660 \mathrm{MW}$ coal generators, $15 \%$ for the older coal plant, and $5 \%$ for gas and hydro plant. Generation plant capacity is modelled according to a binomial distribution using a Monte Carlo simulation (10,000 iterations per plant portfolio). Data is then collated and assembled in descending order to derive the appropriate confidence limits for hedging purposes. Here, we assume that generation portfolios will set maximum hedge limits at a PoE90 level of confidence in plant availability. The subsequent results are consistent with the findings in Anderson, Hu and Winchester (2007) in generator hedging behaviour. Capacity contracted via Independent Power Producers (IPP) is assumed to be more aggressive with greater risk at a confidence limit of only PoE80. Table 9 and Figure 6 present the results of the analysis.

\begin{tabular}{|c|c|c|c|c|}
\hline $\begin{array}{l}\text { Power generating } \\
\text { portfolio }\end{array}$ & $\begin{array}{c}\text { Installed } \\
\text { capacity } \\
\text { (MW) }\end{array}$ & $\begin{array}{c}\text { Confidence } \\
\text { limit } \\
(\%)\end{array}$ & $\begin{array}{l}\text { Hedge } \\
\text { capacity } \\
\text { (MW) }\end{array}$ & $\begin{array}{c}\text { Hedged } \\
\text { capacity } \\
(\%)\end{array}$ \\
\hline Delta Electricity & 4,840 & 90.0 & 3,740 & 77.3 \\
\hline Macquarie Generation & 4,750 & 90.0 & 3,605 & 75.9 \\
\hline Eraring Energy & 2,909 & 90.0 & 2,249 & 77.3 \\
\hline Snowy Hydro & 2,256 & 90.0 & 1,754 & 77.7 \\
\hline Aggregate IPP's & 1,310 & 80.0 & 1,170 & 89.3 \\
\hline TOTAL & 16,065 & & 12,500 & rounded \\
\hline PoE 50 Demand & & & 14,500 & \\
\hline Shortfall against PoE50 & & & 2,000 & \\
\hline
\end{tabular}

Aggregate hedge capacity is found to be 12,500MW against a PoE50 demand of 14,500MW. The shortfall of hedge capacity is surprisingly large, at 2000MW. It is beyond the reliable capacity of the QLD and VIC interconnects (1700MW) to reach a PoE50 hedge level let alone PoE10, and additionally, it is not credible to assume that $1700 \mathrm{MW}$ of hedge capacity can be extracted from the tightly-matched QLD and VIC regions. And if system optimal conditions prevailed on the 
supply-side, the shortfall would be even more significant given the above analysis has an 1865MW oversupply of plant per Table 8.

Figure 6: Joint probability distribution of portfolio plant availability levels

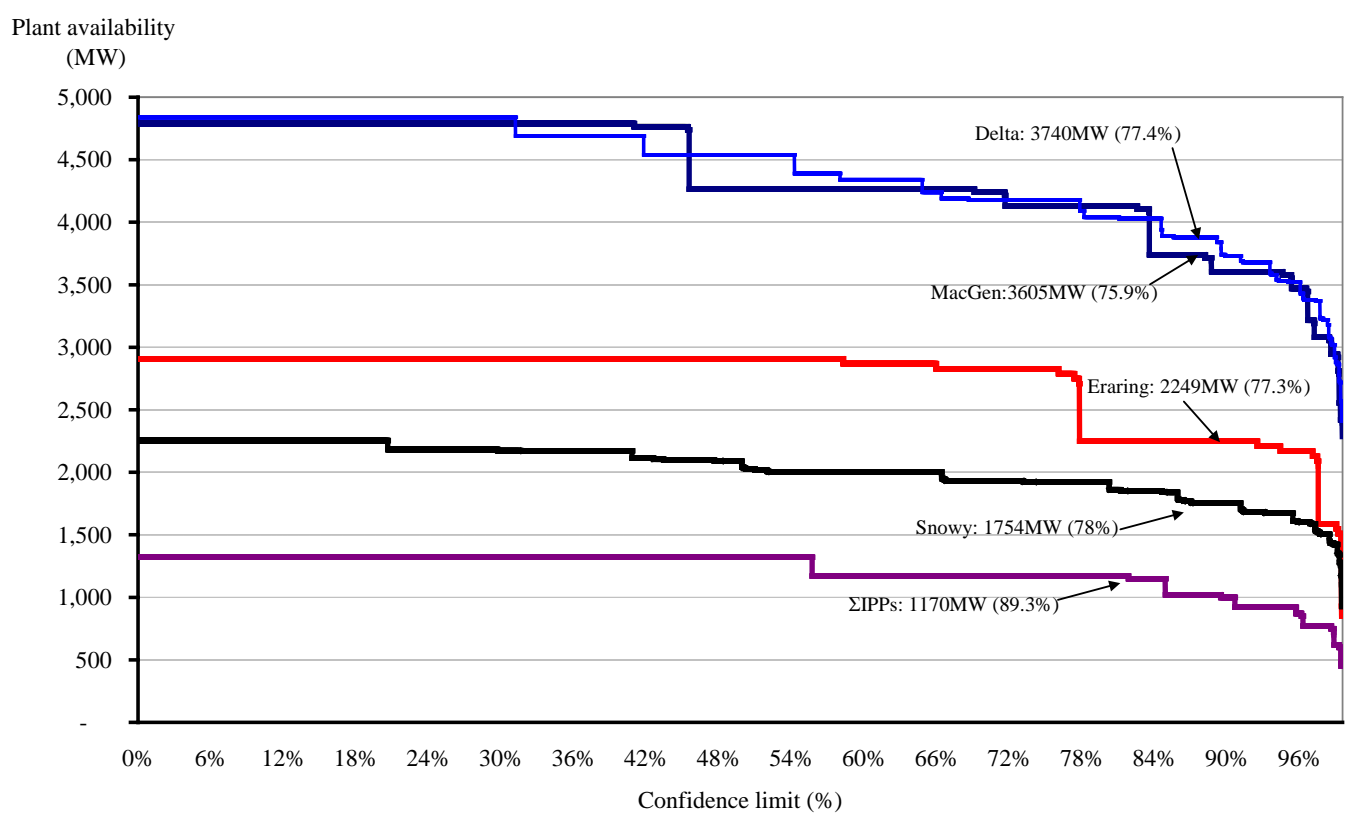

The implications of this analysis seem clear enough. While power system security requires a NSW-domiciled generating plant reserve margin of approximately -3\% (due to reserve sharing across QLD and VIC), systemic security indicates that indigenous hedge capacity must be materially higher, by 2000MW+ bearing in mind the buy-side must structure their book in the presence of uncertainty and the potential for PoE10 electricity loads in very hot and very cold weather conditions.

While unintended, ETEF has had the effect stabilising an inherently 'short' market for regulatory authorities in the current price determination process. But the retirement of this policy in June 2010 is clearly a non-trivial issue and will no doubt exercise the minds of regulatory authorities in future determinations of pricing and policy settings.

\section{Prior lessons from regulatory failures}

IPART's decision to raise prices by $21.7 \%$ was unlikely to be a popular decision with the incumbent government or the electorate. But regulatory failures on price determinations tend to have cascading effects in subsequent years, and it is worth considering the plausible outcomes had they remained on a 7\% trajectory. Two jurisdictions are worthy of analysis to that end; California and Western Australia. In both these markets, retail prices were managed below costreflective levels while wholesale costs increased rapidly.

\subsection{An analysis of the Californian crisis}

The California scenario is an important case study because of the sheer magnitude of the collapse and the unique characteristics that led to what became known as the Californian Energy Crisis. In a similar vein to NSW, the Californian system relied heavily on interconnects for system security. The Californian grid comprised a 45,000MW load with roughly 44,000MW of local generating capacity (coal, gas, nuclear \& hydro) with interconnects to other western states as well as Canada and Mexico. In March 1998, California introduced full retail contestability following two years of structural reform. As part of the changes, electricity prices were frozen at June 1996 levels for 
four years, and additionally, residential and small business customers received a 10-percent rate reduction in their electricity bills. Regulatory authorities had assumed, with considerable justification at the time, that wholesale prices would fall substantially below prevailing market rates. Joskow (2001) noted that the Californian market appeared to be working well during its first two years of operation to 2000, although in 1999 the system operator had become nervous about the slow pace new plant entry.

But by the summer of 2000, the market experienced a substantial increase in the wholesale cost of electricity, with the spot market rising from about $\$ 30 / \mathrm{MWh}$ in 1999 to $\$ 300+/ \mathrm{MWh}$ by the end of 2000. At the time, the California government did nothing to respond to the emerging energy crisis. On the contrary, when retail prices began to increase in summer 2000 in response to wholesale prices, there was loud negative public reaction which led the California legislature to cap prices (Joskow, 2001). The existence of these retail price caps prevented the two large investor owned utilities, Southern California Edison (SCalEd) and Pacific Gas \& Electric (PG\&E) from passing on the high wholesale electricity costs to consumers. Joskow (2001) and Bushnell (2004) noted that both SCalEd and PG\&E were technically insolvent by early-January 2001. In just six months, a relatively successful electricity reform had collapsed and with it two of the largest investor owned utilities in the US.

Analysis by Joskow (2001) and Bushnell (2004) on the conditions that led to the collapse identify seven characteristics; (1) large increases in the demand for electricity; (2) a reduction in imports from neighbouring systems; (3) stalled entry; (4) the emergence of market power; (5) rising prices in the market for natural gas; (6) rising prices in the nitrous oxide emissions permit market; and (7) suboptimal activity in the forward market for electricity.

While the exercise of market power might at face value be considered the source of the problem (and indeed made popular through the documentary on the Enron collapse), the literature is clear that this was a second order issue. Joskow and Khan (2001) for example estimated that $1 / 3$ of the increase in wholesale power prices during 2000 was due to market power. As Bushnell (2004) noted, the market didn't count on the effects of emission permit prices rising, the run-up in gas prices from c.\$2.50/GJ to c.\$6.00/GJ, and the effects of stalled entry. But most significantly, as with NSW via ETEF, a growing amount of energy was being purchased from the spot market and the Californian Public Utilities Commission (CPUC) did little to reform retail market institutions to that end. As Joskow (2001) noted, only $12 \%$ of retail customers switched away from default services, thus $88 \%$ remained within the standard franchise tariff framework. And finally, the buy-side was not encouraged to hedge its load, and thus retailers were effectively short against the spot market. The start of the economic phase of the Californian crisis can be pinpointed to mid-2000 with the rise in wholesale prices and the capping of retail prices. But the start of the physical phase of the Californian crisis occurred towards the end of January 2001 - the point at which SCalEd and PG\&E were technically insolvent. It was clear by this point that if no action was taken by the Government, 'the lights would literally go out' (Bushnell, 2004).

With the insolvency of the two utilities, independent generators refused to produce power because as with NEMMCo, the Californian System Operator/Power Exchange did not underwrite counterparty credit. In the event, shutdowns increased from an historical average of 2500MW to about 10 000MW. Consequently, between January and May of 2001, the State of California was forced into the position of becoming the central buyer of electricity and purchased $\$ 8$ billion in forward contracts to stabilise the power grid. ${ }^{20}$ As Bushnell (2004, p.1045) noted:

\footnotetext{
${ }^{20}$ This occurred via California Legislature passing Assembly Bill 1X, which among other things allowed the State Government to take over the bulk of the purchasing responsibilities from the two 'financially moribund' utilities (Bushnell, 2004). 
...These perspectives miss the fundamental fact that California is remarkably similar to other markets in all but one crucial respect. While some other markets have experienced disruptions, no market has come close to the levels of market power, financial instability and system reliability problems that characterised the California crisis... The only factor not seen in other markets in the world is the lack of contracts or other forms of long term supply arrangements... The lack of contracts or other long term arrangements are relatively easy to identify as a major contributor to California's problems. Certainly the CPUC did not make it easy for utilities to sign contracts, but it is inaccurate to attribute the lack of contracts to a CPUC ban on such arrangements..."

The relative absence of an active forward wholesale market can thus be considered an important masking of a more problematic underlying market environment (i.e. systemic risk). ${ }^{21}$

\subsection{An analysis of the West Australian crisis}

The origins of Western Australia's (WA) electricity crisis are comparatively easy to trace. Residential tariffs have been frozen for 11 years from 1997/98 largely as a result of government policy. ${ }^{22}$ The first scheduled increase occurred on 1 July 2009 at 20\%. As with California, wholesale electricity prices were expected to decline and for the majority of the past 11 years, and in the main they did. But over the most recent three years, entry conditions changed materially in WA's South West Interconnected System.

Simshauser and Wild (2008) noted that at the start of 2005, the domestic price of natural gas was about $\$ 2.20 / \mathrm{GJ}$ commodity with a haulage cost of approximately $\$ 1.00 / \mathrm{GJ}$, totalling $\$ 3.20 / \mathrm{GJ}$ 'landed'. By 2007, the landed cost had risen to $\$ 7.50 / G J$. There were two reasons for this. First, an unexpected collapse of a key gas resource (East Spar field) severely impacted available supply. Second, gas demand increased when the North West Shelf Joint Venturers expanded their LNG facility (i.e. 'train 5'). At this point, with demand now matching supply, natural gas prices essentially linked to the price of oil via the seaborne LNG 'net-back price'.

Almost half of WA's power is produced by gas-fired generators, and the rise in gas prices has added $\$ 30$ - \$40/MWh to the marginal running costs of gas plant on a base of $\$ 45 / \mathrm{MWh}$.

Throughout the three year period to 2009, rather than keep apace with the rapidly increasing price of natural gas (rising as it was by about $1.50 /$ GJ or c. $\$ 10$ - $\$ 15 /$ MWh per annum), residential tariffs were frozen by policy. As a result, in February 2009 the West Australian Office of Energy recommended that power prices should rise by $116 \%$ over 3 years, starting with a $52 \%$ increase from July 2009 (William and Probyn, 2009). This would be followed by a 26\% rise in 2010 and a $13 \%$ rise in $2013 .^{23}$

With tariffs set below cost, as was the case with SCalEd and PG\&E in California, one of the WA State Owned Utilities (Verve Energy) was technically insolvent by early-2008 as a result. O’Brien (2008, p.1) noted that the Labour Government injected “\$780 million into its struggling electricity generating utility, Verve Energy, to paper over a massive gap between revenue and costs”. And Burrell (2009) noted that Verve Energy would post a \$349m loss in FY09 and about $\$ 1$ billion over the next four years.

\footnotetext{
${ }^{21}$ In March 2001, the CPUC increased retail electricity rates by $46 \%$.

${ }^{22}$ This 11-year freeze is an estimated real price reduction to $2009 / 10$ of about $30 \%$.

${ }^{23}$ The tariff increases from 2009/10 forward are forecasts only, and are based on the impact that network tariffs would have from 2009/10 onwards if the Economic Regulation Authority approves Western Power's Access Arrangement as per its application, and the impacts of an assumed Carbon Pollution Reduction Scheme commencing in 2010/11.
} 


\section{Policy implications and concluding remarks}

This article has found that wholesale prices in NSW had remained constant at \$35-\$40/MWh for most of this decade, and while volatility in 2007 initially appeared to be drought-induced, the runup in plant capital costs and the cost of capital deployed from 2007 enforced what would become a permanent change in price. The long run marginal cost for base plant in 2009 was demonstrated to be in line with the prevailing forward curve, at about \$50/MWh for base load swaps and system average cost increased from about $\$ 46 /$ MWh to about $\$ 60 /$ MWh driven by plant capital costs (up \$10.17/MWh) and the cost of capital (up \$3.70/MWh). The analysis of ETEF customers provided important data which underlined our thematic. ETEF Franchise customer numbers were found to be rising, not falling which does not bode well for a contestable market.

Another important finding contained in this research is the systemic security issue presented in Section 9. Our analysis suggests that there is an indigenous shortfall of 2,000MW+ of hedge capacity against a PoE50 demand. A PoE10 demand would show an even higher shortfall. Clearly further research will be required in this area.

Prior to IPART lifting prices, the parallels between NSW and that of pre-crisis California were striking; rising energy demand, heavy reliance on large imports from neighbouring regions for system security, difficult economic entry conditions given low headroom, increasing exposures to spot prices (via ETEF) and complex State planning conditions, natural gas price forecasts in contango, an imminent emissions trading market, and suboptimal activity in the forward market for electricity, and of course until July 2009, retail tariffs at odds with wholesale market conditions. This would have represented six factors bearing resemblance to the seven characteristics of pre-crisis California, the exception being the matter of market power. But policy markers now have plans for the roll-off of ETEF. Industry is now commissioning additional indigenous capacity. The State is gradually dealing with planning constraints. And IPART dealt to regulated end-user tariffs, albeit a $21.7 \%$ increase will represent a shock to consumers whom have been accustomed to low CPI increases year-on-year for most of the past decade.

This is where the lessons from the WA crisis are important. Retail tariff movements need to keep apace with wholesale market conditions to avoid the advent of an end-user cost shock. Looking forward, there remains upside risks through emissions trading - the effects of which have been ignored in this article - and the subsequent upward pressure the LNG trade in Queensland will place on gas prices, along with a switch from SCpf to CCGT as the optimal post-emissions trading entrant (shifting as it will, the base load entry cost from \$49/MWh to an aggregate \$70$\$ 95 / \mathrm{MWh}$ at $\$ 25 / \mathrm{t}$ of $\left.\mathrm{CO}_{2}\right)^{24}$

\section{References}

Anderson, E., Hu, X. And Winchester, D. (2007), “Forward contracts in electricity markets: the Australian experience”, Energy Policy, vol.35, pp.3089-3103.

ACiL Tasman, (2008), "Fuel and capital costs in the NEM”, ACiL Tasman, Brisbane.

ACiL Tasman, (2009), "Fuel resources, new entry and generation costs in the NEM", ACiL Tasman, Brisbane.

Boiteux, Marcel P. (1949), "La tarification des demandes en pointe: Application de la theorie de la vente au cout marginal”, Revue generale de l'electricite.

\footnotetext{
${ }^{24}$ Table 5 highlights the entry cost of CCGT plant at $\$ 60.14 / \mathrm{MWh}$. With a $\mathrm{CO}_{2}$ footprint of $0.4 \mathrm{t} / \mathrm{MWh}$ and a $\mathrm{CO}_{2}$ price of $\$ 25 / \mathrm{t}$, the aggregate entry cost equates to $\$ 70.14 / \mathrm{MWh}$. If gas prices rise to $\$ 7.50 / \mathrm{GJ}$, the cost of the CCGT plant rises to $\$ 85 / \mathrm{MWh}$ plus $\mathrm{CO}_{2}$. 
Burrell, A. (2009), “Energy bill generates anger in WA”, Australian Financial Review, Tuesday 24 February, p.7.

Bushnell, J. (2004), “California’s electricity crisis: a market apart?”, Energy Policy, 32(9): 1045-1052.

ESAA: Energy Supply Association of Australia, (2003, 2008), ElectricityGas Australia, ESAA Publication, Melbourne.

Fisher, B., Newton, P. and Woolnough, C. (2009), "Review of inputs to cost modelling of the NEM”, Report prepared for the Queensland Competition Authority, Concept Economics Publication, Canberra.

GTW: Gas Turbine World, (2007), “Gas Turbine World Handbook”, Volume 26, Pequot Publishing, Southport.

Joskow, P. (2001), “California’s electricity crisis”, Oxford Review of Economic Policy, 17(3): 365-389.

MacFarlane, I. (2008), “House of Representatives Official Hansard”, No. 12, Thursday 18 September 2008, Commonwealth of Australia, p.7493.

NEMMCo: National Electricity Market Management Company, (2008), “2008 Statement of Opportunities”, NEMMCo Publication, Melbourne.

O’Brien, A. “Families fork out in power scandal”, The Australian, 5 April 2008. Available at http://www.theaustralian.news.com.au/story/0,25197,23487280-2702,00.html. Accessed 5 February 2009.

Officer, R. (1994), “The cost of capital under a dividend imputation tax system”, Accounting and Finance, 34(1), May.

Sainsbury, M. (2008), “Big four banks beat global investment peers”, The Australian, Wednesday April $2^{\text {nd }}$, p.23.

Samuelson, R. (2009), “Economists ignored history”, Australian Financial Review, 6 July 2009, p.55.

Simshauser, P. (2005), "The gains from the microeconomic reform of the power generation industry on East Coast Australia”, Economic Analysis and Policy, 35(1\&2):23-43.

Simshauser, P. (2008), "The dynamic efficiency gains from introducing capacity payments in the NEM Gross Pool”, Australian Economic Review, 41(4):349-370.

Simshauser, P. (2009), “On emissions trading, toxic debt and the Australian power market”, The Electricity Journal, Vol.22, No. 2, pp 9-29.

Simshauser, P. and Wild, P. (2008), “The WA power dilemma”, Working Paper No.10, available from p.wild@uq.edu.au

SKM: Sinclair Knight Mertz, (2007), “Climate change challenges for new power plant”, UBS Energy and Utilities Conference, June 2007, Sydney. (SKM Author: Zauner, R).

Smith, R. (2008), “Clean energy confronts messy reality”, The Wall Street Journal, November 212008.

Standard \& Poor's, (2007), "Increasing construction costs could hamper US utilities plans to build new power generation”, Standard \& Poor’s Publication, New York.

Vaitheeswaran, V. (2001), “Energy: a brighter future? A survey of energy”, The Economist, February 1016, pp. 1-20.

Williams, P. and Probyn, A. (2009), "Power bills set to soar: Barnett”, West Australian, 6 February 2009, p.6. 
Appendix I: Plant capacity in NSW

\begin{tabular}{llccr}
\hline Power Station & Owner & Fuel & Duty & $\begin{array}{r}\text { Capacity } \\
(\text { MW) }\end{array}$ \\
\hline Eraring & Eraring Energy & Coal & Base & 2,640 \\
Bayswater & Macquarie Generation & Coal & Base & 2,640 \\
Liddell & Macquarie Generation & Coal & Base & 2,060 \\
Vales Point B & Delta Electricity & Coal & Base & 1,320 \\
Mt Piper & Delta Electricity & Coal & Base & 1,320 \\
Wallerawang C & Delta Electricity & Coal & Base & 1,000 \\
Smithfield & Marubeni & Gas & Base & 160 \\
Redbank & Babcock \& Brown Power & Coal & Base & 150 \\
Tumut 1 & Snowy Hydro & Hydro & Intermed. & 330 \\
Tumut 2 & Snowy Hydro & Hydro & Intermed. & 286 \\
Munmorah & Delta Electricity & Coal & Intermed. & 600 \\
Tallawarra & TRUenergy & Gas & Intermed. & 400 \\
Tumut 3 & Snowy Hydro & Hydro & Peak & 1,500 \\
Shoalhaven & Eraring Energy & Hydro & Peak & 240 \\
Blowering & Snowy Hydro & Hydro & Peak & 80 \\
Hunter Valley & Macquarie Generation & Diesel & Peak & 50 \\
Hume NSW & Eraring Energy & Hydro & Peak & 29 \\
Uranquinty & Origin Energy & Gas & Peak & 600 \\
Colongra & Delta Electricity & Gas & Peak & 600 \\
Guthega & Snowy Hydro & Hydro & Peak & 60 \\
\hline Total Capacity & & & & 16,065 \\
\hline
\end{tabular}

